\title{
Emotional Difficulties in Adolescence: Psychopathology and Family Interactions
}

\author{
ARTICLE · MAY 2015
}

DOI: 10.9734/INDJ/2015/17789

READS

88

8 AUTHORS, INCLUDING:

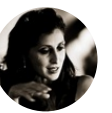

Alessandra Simonelli

University of Padova

62 PUBLICATIONS 19 CITATIONS

SEE PROFILE

Andrea Spoto

University of Padova

38 PUBLICATIONS 106 CITATIONS

SEE PROFILE
Marta Sisti

Infancy Adolescence Family Service, Padua

9 PUBLICATIONS 1 CITATION

SEE PROFILE 


\title{
Emotional Difficulties in Adolescence: Psychopathology and Family Interactions
}

\author{
M. Gatta ${ }^{1 *}$, A. Simonelli ${ }^{2}$, L. Sudati ${ }^{1}$, M. Sisti ${ }^{1}$, L. Svanellini ${ }^{1}$, M. Stucchi ${ }^{1}$ \\ A. Spoto ${ }^{3}$ and P. A. Battistella ${ }^{1}$ \\ ${ }^{1}$ Infancy Adolescence Family Service, ULSS 16 - Woman and Child Health Department, \\ University of Padua, Padua, Italy. \\ ${ }^{2}$ Department of Development and Socialization Psychology, University of Padua, Padua, Italy. \\ ${ }^{3}$ Department of General Psychology, University of Padua, Padua, Italy.
}

Authors' contributions

This work was carried out in collaboration between all authors. Authors MG and PAB designed the study, wrote the protocol, and wrote the first draft of the manuscript. Authors A. Simonelli, A. Spoto and L. Sudati performed the statistical analysis. Authors M. Stucchi, M. Sisti and L. Svanellini collected data, managed database, managed the literature searches. All authors read and approved the final manuscript.

Article Information

DOI: $10.9734 / / N D J / 2015 / 17789$ Editor(s):

(1) Pasquale Striano, Pediatric Neurology and Muscular Diseases Unit, University of Genoa, G. Gaslini Institute, Genova, Italy. Reviewers:

(1) F. E. Okwaraji, University of Nigeria, Nigeria

(2) Anonymous, Israel.

(3) Anonymous, USA.

Complete Peer review History: http://www.sciencedomain.org/review-history.php?iid=1004\&id=29\&aid=9515

Short Research Article

Received $26^{\text {th }}$ March 2015

Accepted $12^{\text {th }}$ May 2015

Published $30^{\text {th }}$ May 2015

\section{ABSTRACT}

Introduction: Several studies on developmental age have investigated aspects relating to emotional competence, and alexithymia in particular, showing that it is associated with behavioral problems in childhood and adolescence.

Some such research has focused on the relationship between emotional difficulties and family interactions assuming a link between the quality of family relationships and a child's emotional competence.

Subjects and Methods: The aims of the present study were: 1) to compare a group of psychiatric adolescents with a group of "healthy" adolescents in terms of any alexithymia and its relationship with the former's psychopathological issues; 2) to clarify the relationship, if any, between psychopathology, alexithymia and family interaction patterns in our sample of psychiatric 
adolescents. The experimental group consisted of 41 psychiatric adolescents and the control group of 41 students matched for gender and age. The Toronto Alexithymia Scale (TAS-20) was used to identify any alexithymic traits, the Youth Self Report (YSR) 11-18 and the CBCL to detect any psycho-behavioral problems, and the Lausanne Trilogue Play (LTP) to analyze family interactions.

Results: There was a higher prevalence of alexithymia among the adolescents with mental health problems than in the control group, and a correlation between their scores for internalizing problems and alexithymia. In the experimental group, adolescents with internalizing problems, somatic complaints and attention difficulties belonged to families revealing high levels of parental conflict. As for alexithymia, adolescents' difficulty identifying emotions correlated significantly with the same trait in their mothers. This feature also seemed to be associated with better family interactions.

Conclusion: Our study confirms the importance of family relationships in the development of emotional skills, and highlights how deficiencies in the development of emotional competence are strongly associated with psychopathologies in adolescence. In the light of these findings, it is advisable in clinical practice to provide psychotherapeutic interventions for teens and their parents.

Keywords: Family dynamics; lausanne trilogue play; adolescence; developmental psychopathology; alexithymia.

\section{INTRODUCTION}

The term alexithymia indicates a difficulty in identifying and expressing one's own emotions, and individuals who suffer from this condition are characterized by an externally-oriented cognitive style and a scarcity of fantasies. In recent years, alexithymia has come to be seen as a transnosographic clinical domain extending in a continuum from normal to pathological, depending on the severity of an individual's difficulty in understanding and communicating their emotional experiences. Alexithymia is therefore a dimensional construct forming part of an impairment that makes it more or less difficult for individuals to enter into contact with their emotions and express their own emotional experiences because they lack a regulatory component of cognitive-verbal type [1,2]. Alexithymia is currently considered a risk factor for a whole array of somatic and mental psychopathological conditions, and there is an abundance of scientific and empirical evidence of this personality trait negatively affecting an individual's health. The alexithymic dimension has been studied mainly in adults [3-10]. It is only in recent years that researchers have begun to focus on the alexithymia construct in childhood and adolescence, considering the general population (seeking epidemiological data on the prevalence of alexithymia by gender, age, sociocultural level and family setting, and specific clinical groups to clarify the relationship between alexithymia and a given psychiatric disorder) [11-15]. In a handful of recent studies, the connection between alexithymia and family interaction patterns has also been investigated, assuming a link between the quality of family relationships and a child's emotional competence, and any onset of a psychopathological condition [16]. In the light of these considerations, the aim of the present work was to shed further light on the relationship between alexithymia, psycho-behavioral disorders and family dynamics in adolescence by means of a case-control study on a group of patients taken into care at a Neuropsychiatry Unit for Children and Adolescents.

\section{MATERIALS AND METHODS}

\subsection{Study Design}

This was a case-control study designed: 1) to ascertain the presence of alexithymia and elucidate its relationship with psychopathological problems by comparing a group of psychiatric adolescents with a group of "healthy" adolescents; 2) to identify the relationship between psychopathology, alexithymia and family interaction patterns in our sample of psychiatric adolescents.

\subsection{Sample}

The experimental group of 41 psychiatric adolescents recruited at the Neuropsychiatry Unit for Children and Adolescents (Padua, Italy) consisted of 22 males (54\%) and 19 females (46\%), with a mean age of 16.05 years (SD 1.987). The control group included 41 students matched pairwise for age and gender who were attending four secondary schools in and around Padua, i.e. 22 males (54\%) and 19 females 
(46\%), with a mean age of 15.71 years (SD: 1.401). The Toronto Alexithymia Scale (TAS-20) was administered to identify any alexithymic traits, the Youth Self Report (YSR) 11-18 and the Child Behavior Check List (CBCL) to detect any psycho-behavioral issues, and the Lausanne Trilogue Play (LTP) to analyze family interactions.

Written informed consent was obtained from patients/students and their parents for the adolescents' participation in the study, which had been approved by our institutional ethical committee.

\subsection{Materials and Measures}

\subsubsection{The toronto alexithymia scale (TAS-20) [17]}

This tool is the outcome of an effort made by a Canadian research team to measure alexithymia traits. The current version consists of 20 items. The Italian translation and validation was completed by Bressi et al. (1996). This is a selfreport questionnaire based on a 5-point Likert scale, where the lowest score means complete disagreement with a given statement, and the highest score indicates total agreement. The TAS- 20 measures the three dimensions of the alexithymia construct (difficulty identifying feelings, difficulty communicating feelings, and externally-oriented thinking). The scores distinguish respondents as not alexithymic, borderline for alexithymia, and alexithymic.

\subsubsection{The child behavior checklist (cbcl) and youth self report 11-18 (YSR) [18]}

These questionnaires are some of the most commonly adopted scales for rating juvenile behavior; they are used internationally in the clinical setting and in research. They are in the form of a questionnaire completed one by the parents $(C B C L)$ and the other by the adolescents (YSR). The questionnaires yield two profiles: one for competences and one for behavioral and emotional problems, which can be assessed as "normal", "borderline" or "clinical" on 8 specific syndrome scales. The syndrome scales relating to the various psychopathological pictures are: anxiety/depression, withdrawal, somatization, social problems, thought-related problems, attention problems, aggressive and rule-breaking behavior. The problems are grouped into: internalizing problems (anxiety, depression, withdrawal, somatization); externalizing problems (aggressive and rule-breaking behavior); and other problems (social problems, thought-related problems, attention problems).

\subsubsection{The lausanne trilogue play (LTP) [19]}

This tool is an innovative method for monitoring and assessing of triadic interactions. The LTP is a procedure designed to monitor the dynamics of family interactions in a fun and stress-free condition. It is administered by a trained professional and the family is asked to organize a game in a series of four stages. In Part I one parent plays with the child while the other looks on; in Part II the parents swap roles; in Part III all three members of the family interact with one another; in Part IV the parents interact with each other and the child looks on. The encoding scheme of the LTP process comprises 10 scales, each defining an observational variable, graded on a Likert scale of 1-10 that defines and assesses the participants' behavior.

\section{RESULTS}

Both qualitative and quantitative analyses were performed on our data. The qualitative analysis was run using descriptive statistics (frequencies and percentages). For the quantitative analysis we used the t-test for independent samples to compare the means obtained on the YSR and CBCL scales (independent variables) in each group (dependent variable). Correlations were used to test for any associations between psychopathological problems (YSR 11-8) and alexithymia (TAS-20) in both the groups. A generalized linear model was constructed to identify any significant differences between the means obtained on the YSR scales, dividing the experimental group into two subgroups according to whether they had non-clinical (NCS) or clinical scores (CS), and comparing the total scores obtained by these two subgroups in Parts I, II, III and IV of the LTP (independent variable).

\subsection{Prevalence of Alexithymia (TAS-20) in the Experimental and Control Groups}

An exploratory analysis based on frequencies, percentages and means was conducted to compare the levels of alexithymia between the cases and controls. Alexithymia was more prevalent in the experimental group $(61 \%, n=25)$ than in the control group $(12 \%, n=5)$.

A contingency table $(2 \times 3)$ relating to the association between the two variables - group (case versus control) and alexithymia 
(alexithymia, borderline and no alexithymia) confirmed a higher prevalence of alexithymia in the experimental group [c2 $(\mathrm{gl}=2 ; \mathrm{N}=82)=$ 21,467; p<.001] (Table 1).

Table 1. Alexithymia in experimental and control groups

\begin{tabular}{llll}
\hline TAS-20 diagnosis & $\begin{array}{l}\text { G Exp } \\
\text { N-\% }\end{array}$ & $\begin{array}{l}\text { G Ctrl } \\
\text { N-\% }\end{array}$ & $\begin{array}{l}\text { Tot } \\
\text { N }\end{array}$ \\
\hline No alexithymia & $9(22 \%)$ & $24(59 \%)$ & 33 \\
Borderline & $7(17 \%)$ & $12(29 \%)$ & 19 \\
Alexithymic & $25(61 \%)$ & $5(12 \%)$ & 30 \\
TOT N. & 41 & 41 & 82 \\
\hline \multicolumn{3}{c}{${ }^{*}$ Legend: G Exp = Experimental group; } \\
\multicolumn{2}{c}{ G Ctrl = Control group; $N=$ Number of subjects }
\end{tabular}

\subsection{Association between Alexithymia (TAS-20) and Psychopathological Problems (YSR 11-18) in the Experimental Group}

A t-test for independent samples was run to compare the means obtained on the YSR and CBCL scales (independent variables) in each group (dependent variable). The control group obtained significantly higher mean scores for Activities [t(78) $=-1,919 ; \mathrm{p}=.059]$ and Total competences $[\mathrm{t}(72)=-1,910 ; \mathrm{p}=.060]$. The control group also obtained a higher mean score than the experimental group for Externalizing problems $[\mathrm{t}(80)=-1,729 ; \mathrm{p}=.088]$, although their mean values were not pathological. The experimental group obtained significantly higher mean values for Social problems $[\mathrm{t}(80)=2,132$; $\mathrm{p}<.05]$, while the control group returned higher mean values for Aggressive and rule-breaking behavior $[\mathrm{t}(65,717)=-2,460 ; \mathrm{p}<.05]$ (Table 2$)$.

Pearson's $r$ coefficient was used to test for any associations between psychopathological problems (YSR 11-18) and alexithymia (TAS-20) in the two groups. Tables 3 and 4 summarize the significant results. In the experimental group the scores on the Externalizing problems scale did not correlate significantly with any of the scores on the TAS-20 scale.

\subsection{Associations between Family Interactions (LTP) and Psycho- pathological Problems (YSR11-18 and $\mathrm{CBCL}$ ) in the Experimental Sample}

First of all, the analysis focused on identifying any differences between the different family configurations, in Parts I, II, III and IV of the LTP process. A generalized linear model was run to reveal any significant differences by comparing the means obtained on the YSR scales - after dividing the experimental sample into two subgroups according to participants' responses in the YSR, i.e. non-clinical scores (NCS) and clinical scores (CS) - and the total scores for each part of the LTP, comparing Parts I, II, III and IV (independent variable).

Table 2. Descriptive statistics for the YSR scores in the two groups

\begin{tabular}{|c|c|c|c|c|c|}
\hline YSR scale & Group & $\mathbf{N}$ & Mean & SD & Error SD \\
\hline \multirow[t]{2}{*}{ Activities } & G Exp & 40 & 36.93 & 10.154 & 1.605 \\
\hline & G Ctrl & 40 & 41.33 & 10.351 & 1.637 \\
\hline \multirow[t]{2}{*}{ Social competence } & G Exp & 41 & 43.00 & 9.479 & 1.480 \\
\hline & G Ctrl & 41 & 44.85 & 7.686 & 1.200 \\
\hline \multirow[t]{2}{*}{ Total competence } & G Exp & 34 & 36.88 & 9.822 & 1.684 \\
\hline & G Ctrl & 40 & 41.13 & 9.258 & 1.464 \\
\hline \multirow[t]{2}{*}{ Internalizing problems } & G Exp & 41 & 59.12 & 12.278 & 1.918 \\
\hline & G Ctrl & 41 & 56.61 & 11.597 & 1.811 \\
\hline \multirow[t]{2}{*}{ Externalizing problems } & G Exp & 41 & 54.85 & 10.446 & 1.631 \\
\hline & G Ctrl & 41 & 58.98 & 11.137 & 1.739 \\
\hline \multirow[t]{2}{*}{ Total problems } & G Exp & 41 & 57.68 & 11.633 & 1.817 \\
\hline & G Ctrl & 41 & 58.10 & 9.589 & 1.497 \\
\hline \multirow[t]{2}{*}{ Social problems } & G Exp & 41 & 58.61 & 9.711 & 1.517 \\
\hline & G Ctrl & 41 & 54.73 & 6.427 & 1.004 \\
\hline \multirow[t]{2}{*}{ Rule-breaking behavior } & G Exp & 41 & 55.85 & 6.167 & .963 \\
\hline & G Ctrl & 41 & 60.44 & 10.22 & 1.596 \\
\hline \multirow[t]{2}{*}{ Aggressive behavior } & G Exp & 41 & 57.78 & 7.647 & 1.194 \\
\hline & G Ctrl & 41 & 59.63 & 8.111 & 1.267 \\
\hline
\end{tabular}

*Legend: G Exp = experimental group; G Ctrl = control group; $N$ = number of subject SD = standard deviation; Error $S D=$ Error standard deviation 
Table 3. Pearson's correlations between TAS-20 and YSR scores (G Exp; $n=41$ )

\begin{tabular}{lllll}
\hline YSR variable & TAS-20 F1 & TAS-20 F2 & TAS-20 F3 & TAS-20 TOT \\
\hline Internalizing problems & $.000^{* * *}$ & $.020^{*}$ & .761 & $.000^{* * *}$ \\
Total problems & $.000^{* * *}$ & $.033^{*}$ & .818 & $.000^{\star * *}$ \\
Anxious/ Depressed & $.000^{* * *}$ & $.021^{*}$ & .498 & $.002^{* *}$ \\
Withdrawn/ Depressed & $.002^{* *}$ & $.048^{*}$ & .701 & $.004^{*}$ \\
Somatic complaints & $.018^{*}$ & .283 & .496 & $.027^{*}$ \\
Social problems & $.001^{* * *}$ & $.018^{*}$ & .920 & $.003^{*}$ \\
Thought problems & $.001^{* * *}$ & .074 & .978 & $.007^{* *}$ \\
Attention problems & $.000^{* * *}$ & .052 & .817 & $.007^{* *}$ \\
Aggressive behavior & .080 & .306 & .289 & $.048^{*}$ \\
Affective problems & $.000^{* * *}$ & $.011^{*}$ & .874 & $.000^{* * *}$ \\
Anxiety & $.001^{* * *}$ & $.045^{*}$ & .655 & $.007^{* *}$ \\
ADHD & $.025^{*}$ & .512 & .696 & .070 \\
\hline
\end{tabular}

${ }^{*}$ Legend TAS-20 = F1- difficulty in identifying feelings; F2- difficulty in communicating feelings to others; F3externally-oriented thinking; Sig: ${ }^{*} p>.05 ;{ }^{* \star} p<.01 ;{ }^{* * *} p<.001$

Table 4. Pearson's correlations between TAS-20 and YSR scores (G Ctrl; $n=41$ )

\begin{tabular}{lllll}
\hline YSR variable & TAS-20 F1 & TAS-20 F2 & TAS-20 F3 & TAS-20 TOT \\
\hline Internalizing problems & $.001^{* * *}$ & $.002^{* *}$ & $.003^{* *}$ & $.000^{* * *}$ \\
Total problems & .053 & .065 & $.004^{* *}$ & $.006^{* *}$ \\
Anxious/ Depressed & $.001^{* * *}$ & $.014^{*}$ & $.003^{* *}$ & $.000^{* * *}$ \\
Withdrawn /Depressed & $.001^{* * *}$ & $.003^{* *}$ & $.019^{*}$ & $.000^{* * *}$ \\
Somatic complaints & $.022^{*}$ & .066 & $.003^{*}$ & $.003^{* *}$ \\
Social problems & .090 & $.050^{*}$ & $.037^{*}$ & $.017^{*}$ \\
Thought problems & .074 & .053 & $.004^{* *}$ & $.005^{* *}$ \\
Attention problems & $.012^{*}$ & .070 & $.001^{* * *}$ & $.001^{* *}$ \\
Aggressive behavior & $.037^{*}$ & $.049^{*}$ & $.001^{* * *}$ & $.002^{* *}$ \\
Affective problems & $.000^{* * *}$ & $.013^{*}$ & $.001^{* * *}$ & $.001^{* * *}$ \\
Anxiety & $.045^{*}$ & .082 & $.014^{*}$ & $.013^{*}$ \\
ADHD & $.025^{*}$ & .512 & $.013^{*}$ & $.047^{*}$ \\
\hline
\end{tabular}

*Legend TAS-20 = F1- difficulty in identifying feelings; F2- difficulty in communicating feelings to others; F3externally oriented thinking; Sig: ${ }^{*} p>.05 ;{ }^{* *} p<.01 ;{ }^{* * *} p<.001$

A first significant difference was seen between the total scores in the various parts of the LTP and the YSR Somatic problems scale $(F=3,420$; $\mathrm{P}<.05)$. The subgroup with $\mathrm{CS}$ for somatic problems obtained a higher mean score than the NCS subgroup for Parts II and III of the LTP, but a lower mean score for Part IV. The NCS subgroup showed a gradual deterioration in total scores from Parts I to IV of the LTP. It is worth noting that co-parenting difficulties emerge more easily in Part IV of the LTP.

A second significant difference was seen between the total scores in the various parts of the LTP and the CBCL scale for Activities ( $\mathrm{F}=$ $3,297 ; p<.05)$. The subgroup with CS had a higher mean score for Activities than the NCS subgroup in Part III of the LTP, but a lower score than the latter in Part IV of the LTP.

Then we considered each LTP family configuration separately, analyzing the four parts of the LTP. A t-test for independent samples was run to compare the means obtained on the YSR scales with the LTP variables. Only the statistically significant results are reported below.

The mean scores on the Activities $[\mathrm{t}(28,553)=$ $2,281 ; p<.05]$ and Total Competences [t(29) $=$ $3,039 ; p<.05]$ scales differed significantly in relation to LTP Affective Warmth and CoConstruction variables' average scores. In particular, the CS subgroup had significantly higher mean scores than the NCS group. This would mean that there is a higher level of emotion sharing in the families of adolescents less involved in activities outside the family.

The Internalizing problems scale showed a significant difference in the average scores for Global Structure [t(32,515 $=-2,357 ; p<.05]$, Conflict and Interference [t $(28,043)=2,070$; $p<.05]$ and Self-Regulation [(37) $=2,612 ; p<.05)$. Families of children with internalizing problems 
scored better for the Global Structure of the task, but worse for conflictual family interactions and the child's self-regulation.

The Attention problems scale showed significant differences between the two subgroups (CS and NCS) for the Conflicts and Interferences variable $[\mathrm{t}(24,274)=2,739 ; \mathrm{p}<.05]$. In particular, the subgroup with clinical scores (CS) for Attention problems had a higher mean score for conflictual family interactions.

A t-test for independent samples was run to compare the means obtained on the $\mathrm{CBCL}$ scales and for the LTP variables. The significant results are described below.

The Activities scale showed a significant difference in the average scores for Scaffolding $[t(35=2,059 ; p<.05]$ and Conflict and Interference $[t(35)=2,362 ; p<.05]$. In particular, families of children who had a clinical score on the Activities scale had more scaffolding difficulties and more conflictual family interactions.

The Somatic complaints scale showed a significant difference in the average scores for Scaffolding $[t(36)=2,423 ; p<.05]$, Self-Regulation $[\mathrm{t}(23,597)=2,734 ; \quad \mathrm{p}<.05], \quad$ Validation Affective $[\mathrm{t}(34,248)=3,475 ; \quad \mathrm{p}<.05]$ and Alliance and Cooperation $\quad[\mathrm{t}(23,076)=2,163 ; p<.05]$. In particular, families of children with a clinical score for somatic complaints had more difficulties with scaffolding, self-regulation and cooperation between parents.

The Aggressive behavior scale showed a significant difference in the average scores for Conflict and Interference $[\mathrm{t}(32,318)=2,176$; $\mathrm{p}<.05]$. In particular, very aggressive adolescents belonged to families with high levels of parental conflict.

\section{DISCUSSION AND CONCLUSION}

The statistical analyses conducted in this study seem to support our hypothesis of a higher prevalence of alexithymia among psychiatric adolescents than in mentally healthy controls. We identified alexithymia in a considerably larger proportion of the experimental group $(61 \%)$ than in the control group (12\%). These results are consistent with published reports on the prevalence of alexithymia among individuals with various somatic and psycho-behavioral disorders $[11,13,20,21]$. When our two groups were tested for psychopathological conditions (YSR), our results indicated that the experimental group was less competent than the control group (on the Social problems scales). For the other YSR syndrome scales, the situation appeared to be more complex. On the Internalizing problems scale, the experimental group obtained higher mean scores than controls, but Externalizing problems were more prevalent in the control group (though their scores were not clinically relevant). The correlation between the TAS-20 scores (for alexithymia) and the YSR scores (for psychopathologies) was positive in both groups. As for the relationship between psychopathological problems and family interactions, we found a variable pattern of results. The presence of somatic complaints seems to be associated with co-parenting conflicts, scaffolding difficulties and, for the adolescents, problems with self-regulation. This result seems interesting and validates the relationship between somatic symptoms and difficulty in managing emotions within the family, even for the parents. The conflict between parents seems to have a central role in other psychopathological problems too, such as: Attention problems, Aggressive behavior and Internalizing problems.

The matter of Internalizing problems warrants particular attention: there is a correlation between internalizing problems and the sharing of emotions within the family. How can we interpret this result? We surmise that adolescents with internalizing problems may be more aware of their difficulties and better able to share them within the family. Another possible interpretation lies in that adolescents with anxiety or withdrawal problems often have parents with similar difficulties (i.e. internalizing problems may be transgenerational) and this could give rise to an emotional resonance that emerges from the LTP. By providing a framework for interpreting family functioning, in such cases the LTP shows that higher levels of psychopathology do not necessarily coincide with worse family interactions.

In conclusion, the association between internalizing or externalizing problems and higher levels of alexithymia supports Taylor's view of alexithymia as a "transnosographic" dimension in relation to both somatic and psychiatric disorders, with which it shares the same affective dysregulation. Our results also show a link between psychopathological problems and family interactions that underscores the need to involve the parents when working with young patients 
[22]. Though our results are consistent with other reports in the literature on emotional difficulties, psychopathologies and family functioning, they should be seen only as preliminary findings that need to be confirmed by larger-scale research efforts, considering larger samples and using longitudinal methods.

\section{CONSENT}

The authors declare that written informed consent was obtained from all patients (or other parties) before their participation in the study, which had obtained the prior approval of the Ethical Committee of the ULSS 16.

\section{COMPETING INTERESTS}

Authors have declared that no competing interests exist.

\section{REFERENCES}

1. Taylor GJ, Bagby RM, Parker JDA. I Disturbi della regolazione affettiva. Roma: Fioriti; 2000.

2. Taylor GJ. Alexithymia: 25 years of theory and research. In: Nyklicek I, Temoshok L, Vingerhoets $A$, editors. Emotional Expression and Health. Hove-New York: Brunner- Routledge; 2004.

3. Lulé D, Schulze UM, Bauer K, Schöll F, Müller S, Fladung AK, Uttner I. Anorexia nervosa and its relation to depression, anxiety, alexithymia and emotional processing deficits. Eat Weight Disord; 2014. (In press)

4. Kusević Z, Marusić K. The relationship between alexithymia and morbidity. Lijec Vjesn. 2014;136(1-2):44-8.

5. Grynberg D, Chang B, Corneille O, Maurage $\mathrm{P}$, Vermeulen $\mathrm{N}$, Berthoz $\mathrm{S}$, Luminet $\mathrm{O}$. Alexithymia and the processing of emotional facial expressions (EFEs): Systematic review, unanswered questions and further perspectives. PLoS One. 2012; 7(8):e42429.

DOI: 10.1371/journal.pone.0042429. [Epub 2012 Aug 23]

6. Bonnet A, Bréjard V, Pasquier A, Pedinielli, JL. Affectivity and alexithymia: Two dimensions explicative of the relationship between anxiety and depressive symptoms. Encephale. 2012;38(3):187-93. DOI: 10.1016/j.encep.2011.03.006. [Epub 2011 Oct 7].
7. Cameron K, Ogrodniczuk J, Hadjipavlou G. Changes in alexithymia following psychological intervention: A review. Harv Rev Psychiatry; 2014. (In press).

8. Scarpazza C, Di Pellegrino G, Làdavas E. Emotional modulation of touch in alexithymia. Emotion; 2014. (In press)

9. Shibata M, Ninomiya T, Jensen MP, Anno $\mathrm{K}$, Yonemoto $\mathrm{K}$, Makino $\mathrm{S}$, Iwaki $\mathrm{R}$, Yamashiro K, Yoshida T, Imada Y, Kubo C, Kiyohara $\mathrm{Y}$, Sudo $\mathrm{N}$, Hosoi $\mathrm{M}$. Alexithymia is associated with greater risk of chronic pain and negative affect and with lower life satisfaction in a general population: The Hisayama Study. PLoS One. 2014;9(3).

DOI: 10.1371/journal.pone.0090984.

10. Van der Velde J, Gromann P, Swart M, Wiersma D, de Haan L, Bruggeman R, Krabbendam L, Aleman A. Alexithymia influences brain activation during emotion perception but not regulation. Soc Cogn Affect Neurosci; 2014. (In press)

11. Gatta M, Canetta E, Zordan M, Spoto A, Ferruzza E, Manco I, Addis A, Dal Zotto L, Toldo I, Sartori S, Battistella PA. Alexithymia in juvenile primary headache sufferers: A pilot study. J. Headache Pain. 2010;12(1):71-80. DOI: 10.1007/s10194010-0248-6. [Epub 2010 Aug 22]

12. Waller E, Scheidt CE. Somatoform disorders as disorders of affect regulation: A developmental perspective. Int Rev Psychiatry. 2006;18(1):13-24.

13. Gatta M, Benanti S, Svanellini L, Penzo M, Balottin L, Battistella PA. Alcohol and emotions in adolescence. GINPE. 2014;1. (In press)

14. Silk JS, Steinberg L, Morris AS. Adolescents' emotion regulation in daily life: Links to depressive symptoms and problem behavior. Child Dev. 2003;74(6): 1869-1880.

15. Izard C, Fine S, Schultz D, Mostow A, Ackerman B, Youngstrom E. Emotion knowledge as a predictor of social behavior and academic competence in children at risk. Psychol Sci. 2001;12(1): 18-23.

16. Kendler KS, Garderc CO, Prescott CA. Toward a comprehensive developmental model for major depression in women. Am J Psychiatry. 2002;159(7):1133-45.

17. Rieffe C, Oosterveld $P$, Terwogt $M$. An alexithymia questionnaire for children: Factorial and concurrent validation results. Pers Individ Dif. 2006;40:123-133. 
18. Achenbach TM, Rescorla LA. Manual for the ASEBA school-age forms \& profiles. Burlington. VT: University of Vermont, Research Center for Children, Youth and Families; 2001.

19. Fivaz-Depeursinge E, Corboz-Warnery A. The Primary Triangle. A developmental systems view of mothers, fathers and infants. New York: Basic Books; 1999.

20. Gatta M, Impollino N, Del Col L, Testa PC, Svanellini L, Battistella PA. Alessitimia e psicopatologia in adolescenza: Studio caso-controllo. Psichiatria dell'Infanzia e dell'Adolescenza. 2012;79:546-566.
21. Zimmermann G. Delinquency in male adolescents: The role of alexithymia and family structure. J Adolesc. 2006;29:321332.

22. Ogrodniczuk JS, Piper WE, Joyce AS. Effect of alexithymia on the process and outcome of psychotherapy: A programmatic review. Psychiatry Res. 2011;190(1):43-8.

DOI:10.1016/j.psychres.2010.04.026. [Epub 2010 May 14].

(c) 2015 Gatta et al.; This is an Open Access article distributed under the terms of the Creative Commons Attribution License (http://creativecommons.org/licenses/by/4.0), which permits unrestricted use, distribution, and reproduction in any medium, provided the original work is properly cited.

Peer-review history:

The peer review history for this paper can be accessed here: http://www.sciencedomain.org/review-history.php?iid=1004\&id=29\&aid=9515 